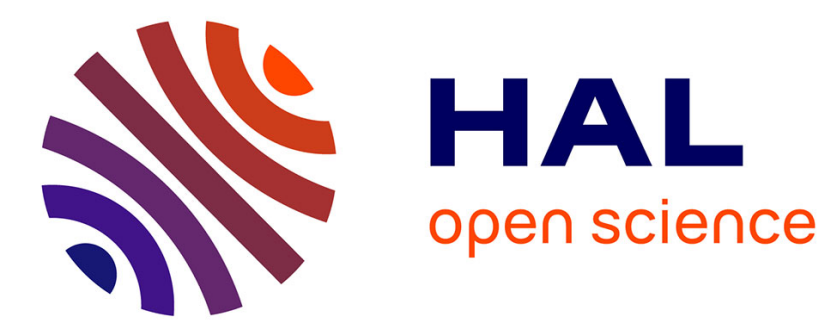

\title{
SPECIFIC HEAT OF (Ce, La) Ru2Si2 AT HIGH MAGNETIC FIELDS
}

\author{
R. Fisher, N. Phillips, C. Marcenat, J. Flouquet, P. Haen, P. Lejay, J.-M.
} Mignot

\section{- To cite this version:}

R. Fisher, N. Phillips, C. Marcenat, J. Flouquet, P. Haen, et al.. SPECIFIC HEAT OF (Ce, La) Ru2Si2 AT HIGH MAGNETIC FIELDS. Journal de Physique Colloques, 1988, 49 (C8), pp.C8-759C8-760. 10.1051/jphyscol:19888342 . jpa-00228519

\section{HAL Id: jpa-00228519 https://hal.science/jpa-00228519}

Submitted on 1 Jan 1988

HAL is a multi-disciplinary open access archive for the deposit and dissemination of scientific research documents, whether they are published or not. The documents may come from teaching and research institutions in France or abroad, or from public or private research centers.
L'archive ouverte pluridisciplinaire HAL, est destinée au dépôt et à la diffusion de documents scientifiques de niveau recherche, publiés ou non, émanant des établissements d'enseignement et de recherche français ou étrangers, des laboratoires publics ou privés. 


\title{
SPECIFIC HEAT OF (Ce, La) $\mathrm{Ru}_{2} \mathrm{Si}_{2}$ AT HIGH MAGNETIC FIELDS
}

\author{
R. A. Fisher $\left({ }^{1}\right)$, N. E. Phillips $\left({ }^{1}\right)$, C. Marcenat $\left({ }^{1,2}\right)^{*}$, J. Flouquet $\left({ }^{2}\right)$, P. Haen $\left({ }^{2}\right)$, P. Lejay $\left({ }^{2}\right)$ \\ and J.-M. Mignot $\left({ }^{2}\right)$ \\ $\left.{ }^{1}\right)$ Materials and Chemical Sciences Division, LBL, Berkeley CA 94720, U.S.A. \\ (2) CRTBT **CNRS, BP $166 \times 38042$ Grenoble, France
}

\begin{abstract}
Specific heat $(C)$ measurements on $\mathrm{Ce}_{1-x} \mathrm{La}_{x} \mathrm{Ru}_{2} \mathrm{Si}_{2}$ were made in order to observe the change in $C$ on going from a long range magnetically ordered system $(x \geq 0.08)$ to a paramagnetic system. Magnetic field measurements of $C$ show that a maximum of the effective mass occurs at the metamagnetic-like transition.
\end{abstract}

The compound $\mathrm{CeRu}_{2} \mathrm{Si}_{2}$ exhibits interesting magnetic features [1]. Its magnetization for $H$ parallel to the tetragonal $c$-axis $(M)$ displays a metamagneticlike transition at $H_{\mathrm{M}} \approx 8 \mathrm{~T}$, although no long range magnetic order could be detected. This field corresponds to the quenching of the antiferromagnetic (AF) correlations occuring below $60 \mathrm{~K}$ [2]. In reference [1] it was argued by comparing the temperature dependences of the resistivity at various fields that the electronic effective mass $m^{*}$ would go through a maximum at $H_{\mathrm{M}}$. In order to check this suggestion, we have performed specific heat measurements on single crystals of $\mathrm{Ce}_{1-x} \mathrm{La}_{x} \mathrm{Ru}_{2} \mathrm{Si}_{2}(x=0,0.05,0.10$ and 0.13$)$. Substituting La for Ce reduces $H_{\mathrm{M}}[3]$ and induces antiferromagnetic (AF) order for $x \geq 0.08$ [4]. The corresponding critical fields are respectively $7.9,5.7,3.8,3.65 \mathrm{~T}$ at $\approx 1.4 \mathrm{~K}$ (i.e. below $T_{\mathrm{N}}$ for the two last systems) [3]. For $H=0$, the measurements extended from $\approx 0.1 \mathrm{~K}$ to $\approx 30 \mathrm{~K}$. Magnetic fields up to $7.5 \mathrm{~T}$ were applied along the $c$-direction for $T \geq 0.4 \mathrm{~K}$.

The $H=0$ data are displayed as $C$ vs. $T$ (up to $16 \mathrm{~K}$ ) in figure $1 \mathrm{a}$; figure $1 \mathrm{~b}$ shows $C / T$ vs. $T$ up to $9 \mathrm{~K}$. These data are consistent with previous results for polycrystals [5]. The value of $C / T$ extrapolated to $T=0\left(\gamma_{0}\right)$ increases from $360 \mathrm{~mJ} \mathrm{~mol}^{-1} \mathrm{~K}^{-2}$ for $x=0$ to $585 \mathrm{~mJ} \mathrm{~mol} \mathrm{~m}^{-1} \mathrm{~K}^{-2}$ for $x=0.1$ and then decreases again. $\gamma_{0}$ may reach a critical value $\gamma_{0 \mathrm{c}} \approx 600 \mathrm{~mJ} \mathrm{~mol}^{-1} \mathrm{~K}^{-2}$ at the magnetic - non magnetic (M-NM) transition which occurs near $x=0.08$ as shown by neutron diffraction experiments [4]. Indeed, for $x=0.13, \mathrm{AF}$ ordering leads to a peak in $C$ at $T_{\mathrm{N}}=3.8 \mathrm{~K}$. This anomaly is very similar to that reported [6] for $\mathrm{CePb}_{3}$, a typical long range magnetically ordered heavy fermion compound. Although no peak in $C(T)$ is observed for $x=0.1$, it is worth noticing the similarity between the $x=0.1$ and $x=0.13$ data in the $C / T$ representation, i.e. a sharp increase on cooling followed by an almost flattening (see Fig. 1b). This suggests that our $x=0.1$ crystal orders below

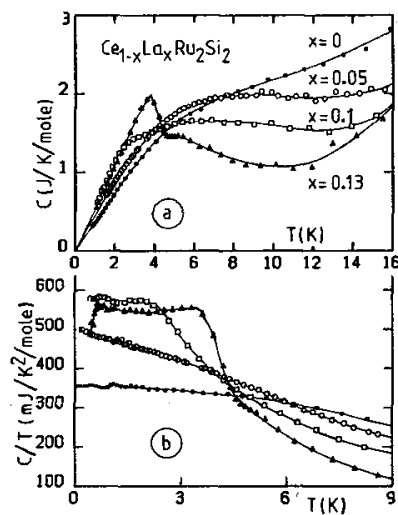

Fig. 1. - Specific heat of single crystals of $\mathrm{Ce}_{1-x} \mathrm{La}_{x} \mathrm{Ru}_{2} \mathrm{Si}_{2}$. a) as $C$ vs. $T:(\bullet) x=0,(0) x=0.05$, (a) $x=0.1$ and $(\Delta) x=0.13$; b) as $C / T$ vs. $T$ below $9 \mathrm{~K}$.

$\approx 2.5 \mathrm{~K}$ which is consistent with $T_{\mathrm{N}}=2.7 \mathrm{~K}$ determined by neutron experiments [4]. On the non magnetic side of the M-NM transition ( $x=0$ and 0.05$)$, the smooth increase of $C / T$ on cooling is very similar to that reported [7] for $\mathrm{CeCu}_{6}$.

Figure 2 shows the field dependence of $\gamma_{0}$. A clear increase of $\gamma_{0}$ towards $H_{\mathrm{M}}$ is observed for the two NM compounds. For $x=0.05$ for which it was possible to perform experiments well above $H_{\mathrm{M}}, \gamma_{0}(H)$ goes through a maximum at a field of $\approx 5.5 \mathrm{~T}$, consistent with the value of $H_{\mathrm{M}}$ derived from magnetization data [3]. While $\gamma_{0}=500 \mathrm{~mJ} \mathrm{~mol}^{-1} \mathrm{~K}^{-2}$ at $H=0$, $\gamma_{0}\left(H_{\mathrm{M}}\right)=655 \mathrm{~mJ} \mathrm{~mol}^{-1} \mathrm{~K}^{-2}:$ an increase of $30 \%$. Magnetization experiments at $1.5 \mathrm{~K}$ lead to an increase of the differential susceptibility $\chi=\partial M / \partial H$ by a factor of 2.7 at $H_{\mathrm{M}}$. Such a dependence of $\gamma_{0}$ with $H$ stresses the importance of the magnetic correlations [1, 2]. $\gamma_{0}\left(H_{\mathrm{M}}\right)=655 \mathrm{~mJ} \mathrm{~mol}^{-1} \mathrm{~K}^{-2}$ is roughly the same value as the critical value $\gamma_{0 c}$ defined above, which suggests that this critical magnitude of $\gamma_{0}$ drives the

\footnotetext{
*Present address: Dept. Mat. Cond., University of Gencva, Switzerland

* 'Laboratoire associé à l'Université Joseph Fourier, Grenoble, France.
} 


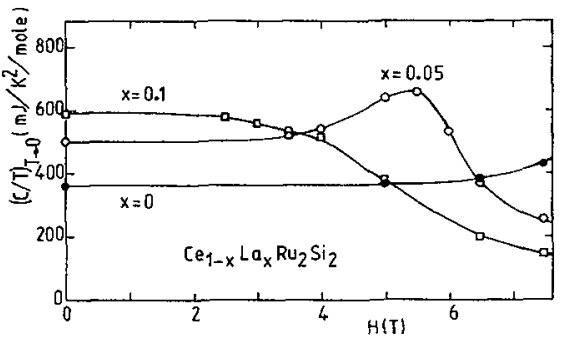

Fig. 2. - Field variation of $C / T$ extrapolated at $T \rightarrow 0 \mathrm{~K}$. Same symbols as in figure 1 .

magnetic instabilities induced either by $H$ or by addition of La.

No maximum in $\gamma_{0}(H)$ can be seen for $x=0.1$. This may be due to the fact that $\gamma_{0}$ is already very close to $\gamma_{0 c}$. However, the occurrence of a new feature (the existence of maxima in the $C / T$ vs. $T$ curves in magnetic fields, connected to the crossing of lines of the $(H, T)$ magnetic phase diagram [3]) prevents accurate extrapolations of $C / T$ to $T=0$, making measurements at lower temperatures desirable.

Finally, $\gamma_{0}(H)$ decreases rapidly with $H$ above $H_{\mathrm{M}}$ where high magnetic polarization is achieved. Further studies of these polarized phases will lead to a better understanding of the heavy fermion compounds.

\section{Acknowledgements}

Work ar Berkeley supported by the Director, Office of Energy Research, Office of Basic Energy Sciences, Material Science Division of the U.S. Department of Energy under contract DE-AC03-76SF00098.
[1] Haen, P., Flouquet, J., Lapierre, F., Lejay, P. and Remenyi, G., J. Low Temp. Phys. 67 (1987) 391.

[2] Regnault, L.-P., Erkelens, W. A. C., RossatMignod, J., Lejay, P. and Flouquet, J., Phys. Rev. $B 38$ (1988) 4481;

Jacoud, J. L., Regnault, L. P., Rossat-Mignod, J., Vettier, C., Lejay, P. and Flouquet, J., ICNS'88, to be published in Physica $B$.

[3] Haen, P., Lapierre, F., Kappler, J.-P., Lejay, P., Flouquet, J. and Meyer, A., J. Magn. Magn. Mat. 76 \& 77 (1988) 143;

Haen, P., Kappler, J.-P., Lapierre, F., Lehmann, P., Lejay, P., Flouquet, J. and Meyer, A., this Conf.

[4] Quezel, S., Burlet, P., Jacoud, J.-L., Regnault, L.P., Rossat-Mignod, J., Vettier, C., Lejay, P. and Flouquet, J., J. Magn. Magn. Mat. 76 \& 77 (1988) 403.

[5] Besnus, M.-J., Kappler, J.-P., Lehmann, P. and Meyer, A., Solid State Commun. 55 (1985) 779; Besnus, M. J., Lehmann, P. and Meyer, A., J. Magn. Magn. Mater. 63 \& 64 (1987) 323;

Lehmann, P., Thesis, Strasbourg (1987).

[6] Lin, C. L., Teter, J., Crow, J. E., Mihalisin, T., Brooks, J., Abou-Ali, A. I. and Stewart, G. R., Phys. Rev. Lett. 54 (1985) 2541;

Ravex, A., Morin, P. and Flouquet, J., unpublished.

[7] Amato, A., Jaccard, D., Flouquet, J., Lapierre, F., Tholence, J. L., Fisher, R. A., Lacy, S. E., Olsen, J. A. and Phillips, N. E., J. Low Temp. Phys. 68 (1987) 371. 